\title{
Manufacturing feature-based cost estimation of cast parts
}

\author{
*Muhammad Sajid, Ahmad Wasim , Salman Hussain, Mirza Jahanzaib \\ Department of Industrial Engineering, University of Engineering and Technology, Taxila, Pakistan, 47050
}

\begin{abstract}
Seventy percent of new product cost is committed in the design phase. Therefore, the cost needs to be minimized. Incorporating accurate cost estimation capabilities into manufacturing processes can help industries to minimize the cost and optimize the design. The casting process has been employed as a key process to manufacture parts having the advantage of low cost and customized products in foundry industry. This paper presents a cost estimation system for the casting process based on the design features, which incorporates the casting information at the design stage of castings. It aims to deliver the best cost-effective choice for casting design features of a product. Two kinds of knowledge, namely economical knowledge (describing the relation between the casting design considerations and the cost) and technical knowledge (involving the material of the casting features) were structured in this research work. On the basis of the minimum product cost, casting material selection can be carried out in detail. The developed system has been validated through an industrial case study.
\end{abstract}

Key words: cost estimation model; casting process; design features

CLC numbers: TG248 Document code: A Article ID: 1672-6421(2018)06-464-06

$\mathrm{F}$ oundry industry is being improved by the development of advanced technologies in casting processes. Many companies struggle to apply the innovative techniques, technologies and systems to win the intense competition in the changing global market. There is about $70 \%$ of product cost committed in the design phase ${ }^{[1]}$, so designers take this phase critically and pay a special attention to avoid interruption in the casting of products.

The cost estimation of casting processes can optimize the product design at the initial stages of casting processes before the production starts. This may also provide a decision support to the designer regarding both the cost and the casting process capabilities. Therefore, leading casting companies have a requirement to develop tools and techniques which can estimate the product cost at the initial design stage to ensure that the advance casting processes can meet the expected specifications.

Shehab et al. ${ }^{[2]}$ described the cost estimation as an approach to forecasting the cost associated to actions

\footnotetext{
* Muhammad Sajid

Male, born in 1993, MSc, Ph.D, Research Scholar. Research interests: Development of an innovative cost estimation system for casting processes, product design and development.

E-mail: sajid.malik@uettaxila.edu.pk

Received: 2018-07-09; Accepted: 2018-08-08
}

before the final implementation. Niazi et al. ${ }^{[3]}$ classified the cost estimation techniques as quantitative and qualitative techniques. Quantitative cost estimation techniques are associated with detailed estimations of cost due to the availability of a large amount of data. Qualitative cost estimation techniques are suitable for a rough estimate of cost in the case of a limited amount of available data. These techniques are applicable at an initial stage of the product design. Feature-based cost estimation is a quantitative cost estimation technique including the identification of features related to the manufacturing process and interrelating it with the $\operatorname{cost}^{[4]}$. In this perspective, the practice of feature concept is mostly agreed by many researchers. Chayoukhi et al. ${ }^{[5]}$ used the feature concept to develop the cost estimation model. The developed model decomposed the structure into a set of assemblies. Each assembly was modelled by using one or several preparation features and process features which led to the generation of several manufacturing processes associated with a cost model. Chayoukhi et al ${ }^{[6]}$ proposed a cost estimation technique on the basis of the feature model. It was developed to evaluate the manufacturing cost of joints preparation for gas metal arc welding. Bouaziz et al. ${ }^{[7]}$ used the machining features to develop a cost estimation system of dies manufacturing. On the basis of design features and tooling parameters, an integrated framework for die 
and mould cost estimation was developed by Mukherjee et al. with the concept of cost drivers (geometric features) and cost modifiers (tooling parameters) used in the research ${ }^{[8]}$. Wasim et al. ${ }^{[9]}$ used a feature based cost estimation approach to develop a cost modelling system for resistance spot welding. The proposed system was used to provide pre-emptive decision making and mistake exclusion in the early design stage of product and process development. A similar feature based approach was used by Masmoudi et al. ${ }^{[10]}$ and Zhang et al. ${ }^{[1]}$ as they developed cost estimation models for welding and machined parts, respectively.

Little or no study was found regarding any cost model or cost estimation technique for the casting process using the featurebased approach in the above researches. Choughle et al. ${ }^{[12]}$ used a combination of analytic and parametric cost estimation techniques to develop a hybrid model of cost estimation for casting process in an incorporated product and process design (PPD) environment. Additionally, only focusing on the "design to cost" concept cannot adapt to constant changes of customer demands and needs, and this concept (design to cost) took into account the set of activities with an emphasis on the cost limits ${ }^{[13]}$. This leads to the time extension of design because the iterations were required to agree with the set target. Thus, a cost estimation model should be capable of supporting the designers to optimize the casting design features while considering the other important values such as cost, time, weight, and ultimate tensile strength (UTS) of the product.

The current developments of the cost estimation approaches incorporate technical and geometric features of the product. In the field of casting, the tools for assessing the product cost are not commonly used and there exists a limited research on casting methods. To address this limitation, a system for cost estimation of cast parts was proposed in this work. The system was developed in Microsoft Visual Studio 2016 using C\# language and Microsoft SQL server database. The proposed system took the design features and associated material into consideration and fulfilled the minimum cost criteria along with other values required by the customer.

\section{Cost estimation methodology for cast parts}

In order to extract the costing knowledge of cast parts, the system requires the representation of assembly. The developed system focuses on attributes which affect the total cost of the product including design features (type of material required and geometric features) and sand casting process variables. Using these design features and process variables, feature-based cost estimation has been performed in this work. The cost estimation methodology was divided into the following stages (Fig. 1):

(1) Disintegrating the product into sets of part assemblies;

(2) Taking each part one by one and forming the inventory of casting design features;

(3) Selecting the casting process followed by specifying the casting material for each part;

(4) Specifying the casting design considerations against the selected manufacturing process;

(5) Calculating the time and cost against each material;

(6) Taking the next part/assembly and repeating the procedure from step 1 to 5 until time and cost of all assemblies are calculated;

(7) Computing the optimum cost, time and other values of the product.

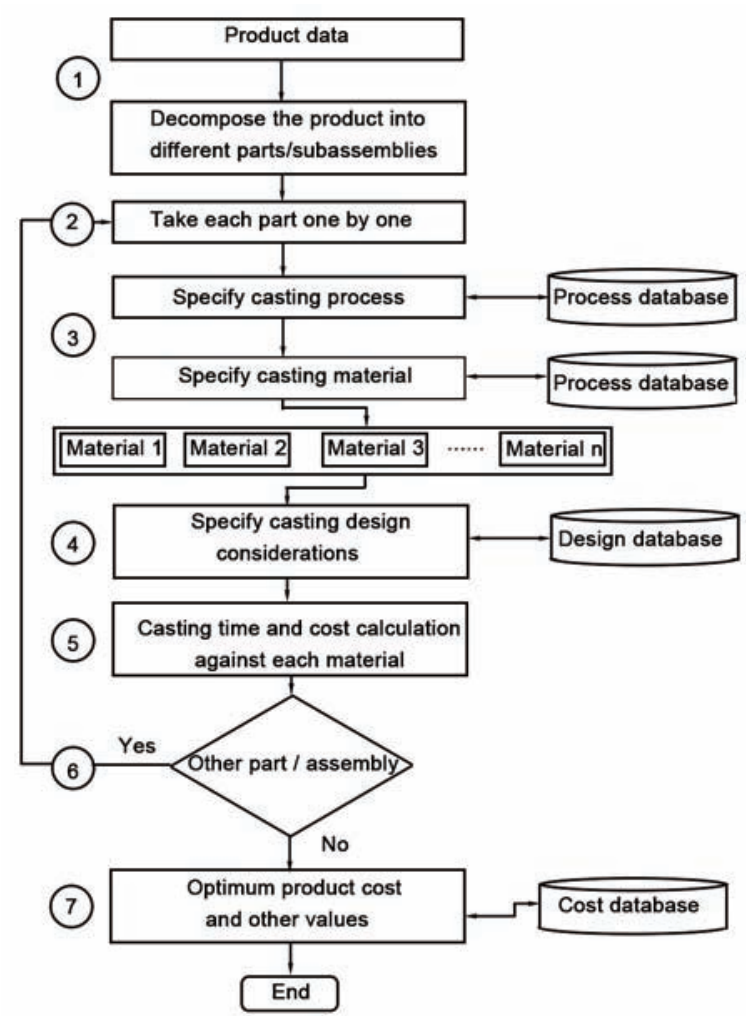

Fig. 1: Algorithm of cost estimation system for casting process

\section{Cost estimation system for casting process}

In order to develop the cost estimation for the casting process, casting design features have been considered in this work. Casting design features include the design features of a gating system (pouring basin, sprue, runner, sprue well and ingates) that regulates the proper flow of molten material into the mould cavity. The casting design feature comprises of two operations: (i) preparation for the mould (to give proper flow of molten material) and (ii) mould filling and solidification. The design features for a sand casting process have been provided in Table 1. Two data sets were used for casting design features. The first data set was related to the description of the geometric specifications and material for a specific product, whereas, the second data set was associated with the casting process. The preparation features for casting parts of the system have been illustrated in Fig. 2.

\section{Casting design feature preparation process}

As already discussed, the preparation process of casting design 
Table 1: Casting design features

\begin{tabular}{|c|c|}
\hline Design features & Symbol (unit) \\
\hline Sprue height & $h(\mathrm{~mm})$ \\
\hline Effective sprue height & $H(\mathrm{~mm})$ \\
\hline $\begin{array}{l}\text { Distance between sprue top and } \\
\text { pouring basin top surface }\end{array}$ & $h_{1}$ \\
\hline $\begin{array}{l}\text { Distance between sprue bottom and } \\
\text { pouring basin top surface }\end{array}$ & $h_{2}$ \\
\hline Total height of mould cavity & $c(\mathrm{~mm})$ \\
\hline Sprue top area & $A_{1}\left(\mathrm{~mm}^{2}\right)$ \\
\hline Sprue exit area/Choke area & $A_{2}\left(\mathrm{~mm}^{2}\right)$ \\
\hline Flow loss factor & $F I_{f}$ \\
\hline Gating system type & Top gating, bottom gating \\
\hline $\begin{array}{c}\text { Total weight of molten metal flowing } \\
\text { through choke section }\end{array}$ & Wc (kg) \\
\hline Material density & $\rho\left(\mathrm{kg} \cdot \mathrm{mm}^{-3}\right)$ \\
\hline Pouring time & Pt (seconds) \\
\hline Gravity acceleration & $g\left(\mathrm{~mm} \cdot \mathrm{sec}^{-2}\right)$ \\
\hline Radius of sprue inlet & $R i$ \\
\hline Radius of sprue outlet & Ro \\
\hline Runner Length & $L(\mathrm{~mm})$ \\
\hline Runner width & $W(\mathrm{~mm})$ \\
\hline Runner Thickness & $T(\mathrm{~mm})$ \\
\hline Runner cross sectional area & $R a\left(\mathrm{~mm}^{2}\right)$ \\
\hline Ingates cross sectional area & la $\left(\mathrm{mm}^{2}\right)$ \\
\hline Sprue well cross sectional area & $S W a\left(m^{2}\right)$ \\
\hline Value of gating ratio for runner & $R r$ \\
\hline Value of gating ratio for ingates & $R i$ \\
\hline Sprue well depth & $S W d(\mathrm{~mm})$ \\
\hline
\end{tabular}

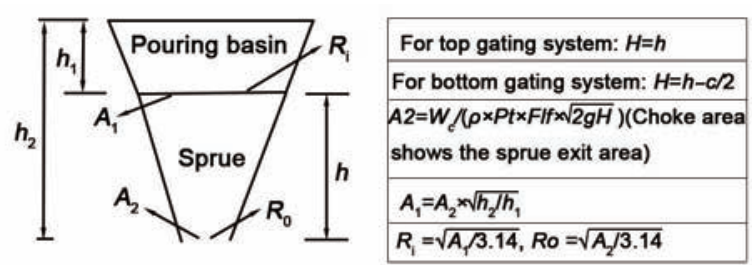

Sprue preparation features

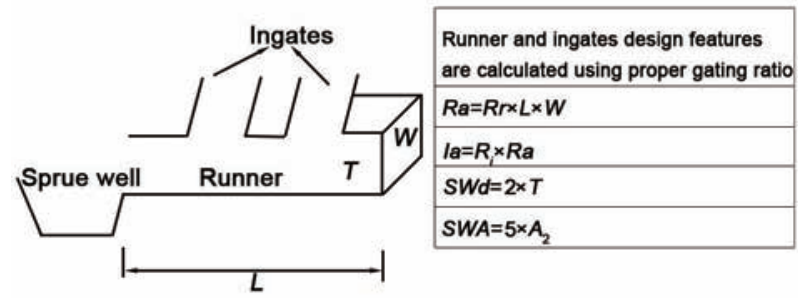

Runner, ingates and sprue well preparation features

Fig. 2: Preparation features of casting parts of cost estimation system

features involves casting mould features design and process parameter feature design. The system was designed to compare different materials and select the best material by considering the criteria of minimum cost and other associated values such as time, weight and production rate of product.
The manufacturability of various materials must follow basic rules such as machine and material availability. For example, if the furnace with desired material melting temperature does not exist, alternative options (furnaces) should be applied with the melting temperature equal or greater than the melting temperature of selected material. Therefore, a knowledge database has been developed to identify the castability of a specific designed product. This will enable the designers to have clear knowledge about the availability of specific machines and tools that are compulsory for the accomplishment of a selected casting process.

\section{Casting time and cost estimation function}

\subsection{Casting time function}

The casting time includes the mould filling time, pouring time and solidification time, where the mould filling time is the time to completely fill the mould cavity, the pouring time is the time to pour the molten metal into the mould cavity, and the solidification time is the time to completely solidify the mould material before starting post casting operations. Other times are also included in the sand casting process such as precasting processing time and post-casting operations time. Since this work only focuses on the manufacturing cost extracted from product design features, pre-casting processing time and post casting operations time were not considered in this work. Equations (1-3) estimate the casting time for the mould filling, metal pouring and metal solidification.

The mould filling time is calculated through the following equation:

$$
T_{\text {filling }}=V_{\mathrm{c}} / Q_{\max }
$$

where $T_{\text {filling }}$ is the mould filling time in sec, $V_{\mathrm{c}}$ is the casting volume $\left(\mathrm{mm}^{3}\right)$ and $Q_{\max }$ is the metal flow rate in $\mathrm{mm}^{3} \cdot \mathrm{sec}^{-1}$.

The pouring time is measured by solving the pouring rate expression for time as below:

$$
P t=W / P r
$$

where $P r$ represents the pouring rate in $\mathrm{kg} \cdot \mathrm{sec}^{-1}, P t$ denotes the pouring time in sec, $W$ shows the cumulative weight of the casting, riser and gating system in $\mathrm{kg}$.

The solidification time is calculated through the following expression (Chvorinov's Rule):

$$
\begin{gathered}
T_{\mathrm{sol}}=B\left[\frac{V_{\mathrm{c}}}{S \cdot A}\right]^{\mathrm{n}} \\
B=(\pi / 4)\left[\frac{\rho_{\mathrm{c}} \times H_{\mathrm{f}}}{T_{\mathrm{m}}-T_{\text {initial }}}\right] \times\left[\frac{1}{T C_{\mathrm{m}} \times \rho_{\mathrm{m}} \times H_{\mathrm{s}}}\right]
\end{gathered}
$$

where, $T_{\text {sol }}$ is solidification time in sec, $V_{\mathrm{c}}$ is casting volume in $\mathrm{mm}^{3}, S \cdot A$ is surface area in $\mathrm{mm}^{2}, \mathrm{n}$ is constant and its value lies between $1.5-2.0, B$ is mould constant $\left(\mathrm{sec} \cdot \mathrm{mm}^{-2}\right), \rho_{\mathrm{c}}$ is casting material density $\left(\mathrm{kg} \cdot \mathrm{mm}^{-3}\right), H_{\mathrm{f}}$ is heat of fusion of casting $\left(\mathrm{J} \cdot \mathrm{kg}^{-1}\right)$, $T_{\mathrm{m}}$ is melting temperature $\left({ }^{\circ} \mathrm{C}\right), T_{\text {initial }}$ is room temperature $\left({ }^{\circ} \mathrm{C}\right)$, $T C_{\mathrm{m}}$ is thermal conductivity of mould $\left[\mathrm{W} \cdot\left(\mathrm{m}^{\cdot{ }^{\circ} \mathrm{C}}\right)^{-1}\right], \rho_{\mathrm{m}}$ is density of mould material $\left(\mathrm{kg} \cdot \mathrm{mm}^{-3}\right)$ and $H_{\mathrm{s}}$ is specific heat of mould $\left(\mathrm{J} \cdot \mathrm{kg}^{-1}\right)$. 


\subsection{Casting cost estimation function}

The prediction of casting cost generally depends on the cost drivers relating with the casting process. This research work develops a casting cost estimation function to determine the global cost consumed by the preparation features of casting process. For this purpose, a comprehensive literature review ${ }^{[9,12-14]}$ and meetings with casting experts ${ }^{[9]}$ were conducted to identify the cost drivers. The casting cost drivers include the cost of materials consumed, labour cost, energy cost, overhead expenses and other direct expenses. After the identification of cost drivers, the cost was allocated to each driver. The cost estimation function for casting is defined by the following expression:

$$
T_{\text {cast }}=M_{\mathrm{c}}+L_{\mathrm{c}}+\mathrm{C}_{\mathrm{e}}+O \mathrm{H}_{\mathrm{c}}+O D_{\mathrm{c}}
$$

where $T_{\text {cast }}$ is total cost of casting, $M_{\mathrm{c}}$ is material cost, $L_{\mathrm{c}}$ is the labour cost, $\mathrm{C}_{\mathrm{e}}$ is the energy cost, $O H_{\mathrm{c}}$ is overhead cost and $O D_{\mathrm{c}}$ is other direct cost associated with the casting process.

\subsubsection{Material cost}

The material cost $M_{\mathrm{c}}$ for a sand casting process can be estimated by using the following expression:

$$
\begin{aligned}
M_{\mathrm{c}} & =W_{\text {cast }} \times C_{\mathrm{w}} \\
W_{\text {cast }} & =U_{\text {casted comp }} \times \rho
\end{aligned}
$$

where $M_{\mathrm{c}}$ is material cost in $£, W_{\text {cast }}$ is casting weight $(\mathrm{kg})$, $C_{\mathrm{w}}$ represents the material rate in $£ \cdot \mathrm{kg}^{-1}, V_{\text {casted comp }}$ is casting volume in $\mathrm{mm}^{3}$ and $\rho$ is material density $\left(\mathrm{kg} \cdot \mathrm{mm}^{-3}\right)$.

\subsubsection{Labour cost}

The labour cost can be calculated by the following expression:

$$
L_{\mathrm{c}}=\sum_{\mathrm{i}=1}^{\mathrm{n}} T_{\mathrm{i}} \times N_{\mathrm{i}} \times C l
$$

where $L_{\mathrm{c}}$ represents the labour cost in $£, \mathrm{n}$ is the number of activities, $T_{\mathrm{i}}$ is the time to complete the activity i in seconds, $N_{\mathrm{i}}$ is number of labours involved in completing the activity $i$, and $\mathrm{Cl}$ is labour unit charges in $£ \cdot$ hour $^{-1}$.

\subsubsection{Energy cost}

In the sand casting process, energy is consumed to melt the material. Energy consumption depends upon the melt time, furnace power and furnace efficiency. The energy cost is calculated through the following expression:

$$
E_{\mathrm{c}}=\operatorname{Er} \times\left[\left(V_{\mathrm{f}} \times I_{\mathrm{f}} / \eta_{\mathrm{f}} \times 3600\right)\right] \times T_{\mathrm{m}}
$$

where $E_{\mathrm{c}}$ denotes the energy consumption cost in $£, E_{\mathrm{r}}$ represents the unit energy price in $£$ per kilowatt-hour, $V_{\mathrm{f}}$ is the furnace voltage in volts, $I_{\mathrm{f}}$ is the furnace current in $\mathrm{kA}$, $\eta_{\mathrm{f}}$ is furnace efficiency, $T_{\mathrm{m}}$ is the time to melt the material in seconds.

\subsubsection{Overhead expenses}

Overhead expenses include the administrative overhead expenses and shop overhead expenses. The administrative overhead expenses include the administration cost and depreciation cost. These costs are assigned on the basis of the casting weight and casting hours as given below ${ }^{[12]}$ :

$$
\begin{gathered}
C_{\text {overheads }}=C_{\text {administrative-overheads }}+C_{\text {shop-overheads }} \\
C_{\text {administrative }}=A_{\mathrm{c}} \times D_{\mathrm{c}} \\
A_{\mathrm{c}}=W_{\text {cast }} \times C_{\text {administrative_rate }}
\end{gathered}
$$

$$
\begin{gathered}
D_{\mathrm{c}}=W_{\text {cast }} \times C_{\text {depreciation_rate }} \\
C_{\text {shop-overheads }}=H_{\text {cast }} \times C_{\text {shop_rate }}
\end{gathered}
$$

where, $C_{\text {overheads }}$ is the overhead cost in $£, C_{\text {administrative-overheads }}$ represents the administrative overhead costs, $C_{\text {shop-overheads }}$ denotes the shop overhead costs, $A_{\mathrm{c}}$ is the administrative cost per $\mathrm{kg}, D_{\mathrm{c}}$ is the depreciation cost per $\mathrm{kg}, W_{\text {cast }}$ represents the casting weight in $\mathrm{kg}, C_{\text {administrative rate }}$ is the administrative cost rate in $£ \cdot \mathrm{kg}^{-1}, C_{\text {depreciation rate }}$ is the depreciation cost rate, $H_{\text {cast }}$ depicts the hours to complete the casting and $C_{\text {shop_rate }}$ is the shop cost rate in $£ \cdot$ hour $^{-1}$.

The administration, depreciation and shop rates are calculated by dividing the corresponding costs over the period of time by the total weight/time of castings manufactured during that time $\operatorname{span}^{[12]}$.

\subsubsection{Other direct expenses}

The other direct expenses, $O D_{c}$, include the cost of pattern making, core boxes, cost of using machines, cost of irrecoverable losses during melting, pouring and fettling, research and development cost, and other items which were directly identified for a particular product.

After calculating the total cost of the product, the data is stored in a cost database for future recommendation concerning the cost of a specific product.

\section{Validation through an industrial case study}

To validate the developed system, an industrial case study was carried out. The company selected for the validation used the sand casting process for manufacturing products. The core work of the company was to design and cast pumps for waste water services. It was investigated that the company was employing an inappropriate cost estimation method which resulted in huge overestimates and loss of business. After detailed meetings with the company experts, the following requirements were listed:

(1) The company was looking for a new approach which can help the design team to estimate the cost of alternative casting materials and support decision making about material selection for casting features preparation.

(2) The company was also interested in a new approach which estimates the manufacturing cost of alternative casting processes.

For the current research work, a decision support system capable of selecting casting material with minimum cost is shown in Figs. 3-8. The product selected for validation was a volute casing of a pump (Etanorm pump model) (Fig. 3). The company manufactured the chosen product using the sand casting process.

The costing process for the chosen product for validation began with the decomposition of the product into sets of parts/ subassemblies as explained in the cost estimation methodology (Section 2). Each part/subassembly was taken one by one, 


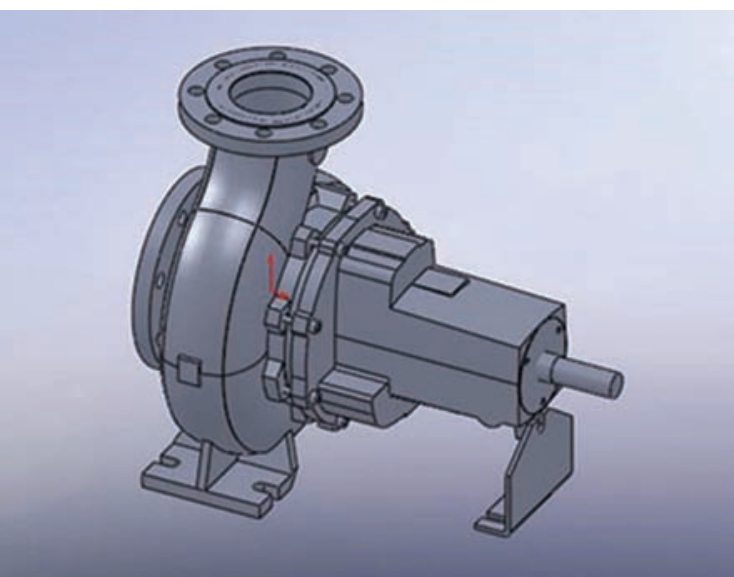

Fig. 3: Volute casing of Etanorm pump assembly

and their possible casting design features were specified. The specified features have been divided into three types, namely; (i) casting process selection, (ii) casting material selection and (iii) casting design consideration. The sand casting process for the Etanorm casing has been selected as demonstrated in Fig. 4.

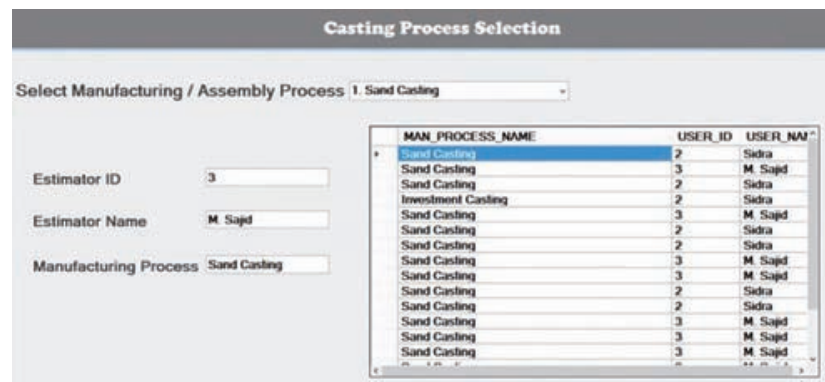

Fig. 4: Casting process selection

After the selection of casting process, the casting material selection was performed. Three types of materials, namely: (i) Aluminium alloy 6063T6, (ii) Aluminium alloy A380 and (iii) cast iron were selected from the material database. These materials were selected due to their wide range of applications including: (i) high strength at low temperature with excellent corrosion resistance, (ii) easily recyclable with substantial scrap value, thus providing both economic and environmental benefits, and (iii) ability to produce complex shapes at low cost ${ }^{[15-17]}$. Other necessary information for casting including physical and chemical properties of the materials has already been provided in the material database of the developed system (Fig. 5).

In the next step, data regarding casting design features was entered into the developed system. Casting design features

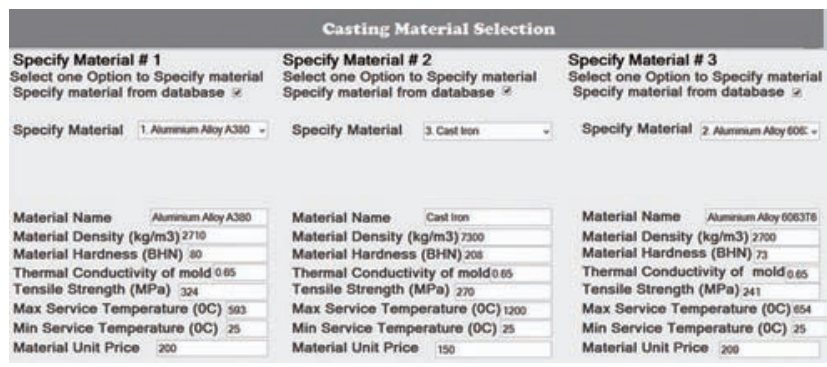

Fig. 5: Casting material selection have been provided in Fig. 6, which include the design of pouring basin, sprue, sprue well, risers and ingates. Number of risers and ingates were specified according to the weight of the casting.

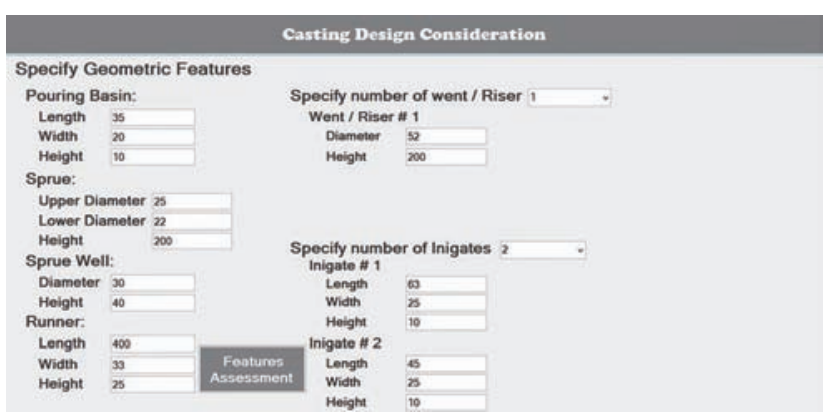

Fig. 6: Casting design consideration features

After specifying the materials, casting process and design features, the system generated time estimates including pouring time, mould filling time and solidification time and total manufacturing. Total manufacturing time was calculated by adding the pouring time, mould filling time and solidification time. At this stage, it was required to input further necessary information into the system including surface area $\left(\mathrm{mm}^{2}\right)$, casting heat of fusion $\left(\mathrm{j} \cdot \mathrm{kg}^{-1}\right)$, density of mould material $\left(\mathrm{kg} \cdot \mathrm{m}^{-3}\right)$ and specific heat of the mould $\left(\mathrm{j} \cdot \mathrm{kg}^{-1}\right)$, as shown in Fig. 7.

\begin{tabular}{|c|c|c|c|}
\hline \multicolumn{4}{|c|}{ Casting Time Calculation } \\
\hline $\begin{array}{l}\text { Pouring Time } \\
\text { Pouring Time } 1 \text { sorswos1 } 00002\end{array}$ & & $\begin{array}{l}\text { Solidification } \\
\text { Solidafication Time } 1\end{array}$ & 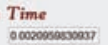 \\
\hline Pouring Time 2 S & & Solidification Time 2 & 15006000010090 \\
\hline 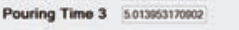 & & Solidification Time 3 & 0.00031252500000 \\
\hline Mold Filling Time & & Manufacturir & ng Time \\
\hline Mold Filling Time 1 1 & & Manufacturing Time 1 & Gaxarasonsas \\
\hline Mold Filling Time 2 & & Manufacturing Time 2 & 162042000312 \\
\hline Mold Filling Time 3 & & Manufacturing Time 3 & 6000401050502 \\
\hline Surface Area (mm2) & neostast & & \\
\hline Casting Heat of Fusion(1/Kg) & 300000 & & \\
\hline Density of Mold Material(Kg/m3) & 1500 & & \\
\hline Specific Heat of Mold(11/Kg) & $\infty$ & & \\
\hline
\end{tabular}

Fig. 7: Casting time calculation

To calculate the total cost of casting parts, the developed system required inputting the values of cost drivers including time to complete the job, labour charges, number of workers/ labours, number of activities, administrative overheads, shop overheads and other direct expenses. Once the values of all cost drivers were fed into the system, the system generated the estimates as shown in Fig. 8.

Among the three materials used for the comparison, aluminium alloy $6063 \mathrm{~T} 6$ was selected because of its minimum

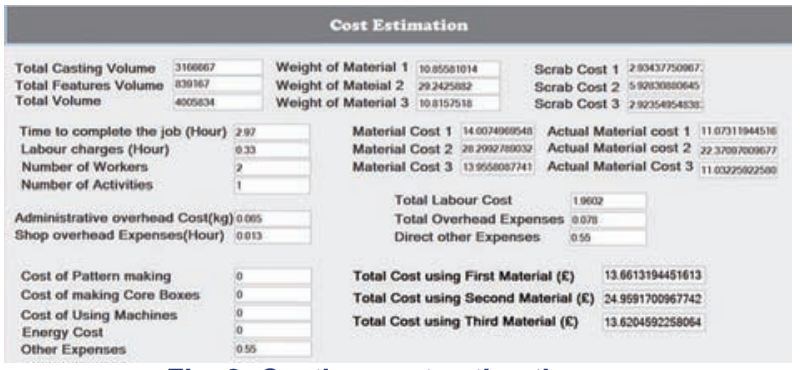

Fig. 8: Casting cost estimation 
cost (£13.62) and fulfilling all other associated values required by the customer. Using the same casting conditions, the calculated cost was compared with the actual cost of the product provided by the company which was $£ 15.89$. The comparison showed least significant difference (14.3\%). This difference in cost estimate may be due to (i) casual mistakes in the casting design feature preparation such as placement of riser on thin sections of casting resulting in early solidification of riser material, abrupt changing in the direction of runners causing low pressure zones which affect mould filling, (ii) faults resulting from the dynamics of the casting process including changes in metal pouring pressure resulting in porosity and shrinkage voids. The system also generated reports to provide a clear comparison between the alternative materials (Fig. 9). The comparison between materials has been shown in Table 2.

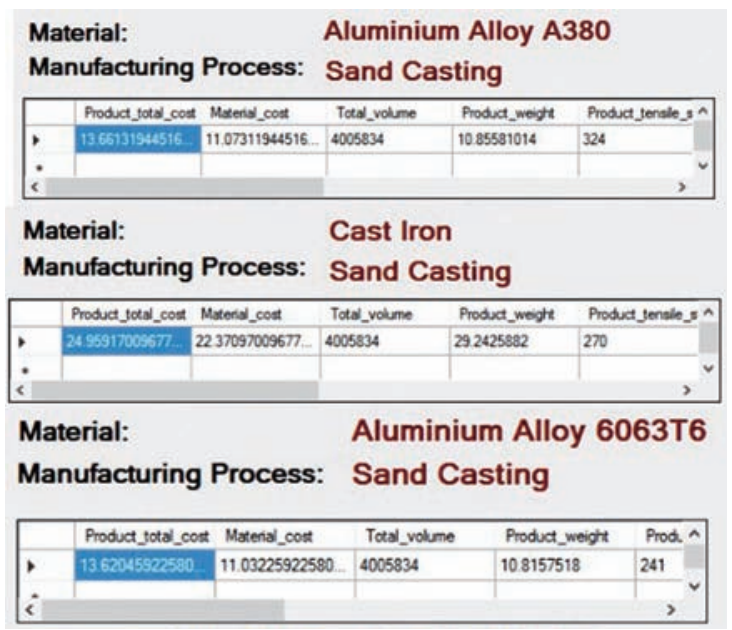

Fig. 9: Summary of results

Table 2: Product cost and other values achieved using alternative materials

\begin{tabular}{|ccccc} 
Materials & $\begin{array}{c}\text { Cost } \\
(\mathbf{(})\end{array}$ & $\begin{array}{c}\text { Manufacturing } \\
\text { time }(\mathbf{m i n})\end{array}$ & $\begin{array}{c}\text { Product } \\
\text { weight } \\
\text { (kg) }\end{array}$ & $\begin{array}{c}\text { Production } \\
\text { rate } \\
\text { (parts per } \\
\text { day) }\end{array}$ \\
\hline $\begin{array}{c}\text { Aluminium alloy } \\
\text { (A380) }\end{array}$ & 13.66 & 6.90 & 10.86 & 4.17 \\
$\begin{array}{c}\text { Cast iron } \\
\text { Aluminium alloy }\end{array}$ & 24.96 & 162.94 & 29.24 & 0.18 \\
6063T6 & 13.62 & 6.89 & 10.81 & 4.17 \\
\hline
\end{tabular}

\section{Conclusion and future recommendation}

This research aimed to develop a manufacturing feature based cost estimation system of cast parts. The developed system enables the designers to estimate the product cost along with other associated values. The system has been developed in Microsoft visual studio 2016 using C\# language and Microsoft SQL server database. Three casting design features including casting process features, casting material features and casting design consideration features have been embedded into the developed system. Casting time and cost functions incorporated into the system help to predict the minimum time and cost of product. Although this research focuses on the sand casting process, it can be extended for other casting processes with minor modifications.

The developed cost estimation system allows the designers (even with little or no knowledge) to make accurate cost estimates for new design features and explore alternative materials. The developed system was evaluated through an industrial case study. It was indicated from the conclusions (drawn from the system) that the proposed system could assist companies to reduce cost and manufacturing time of the product by estimating total manufacturing cost throughout the product development cycle. The authors believe that in addition to the current capability of the developed system, tools will be developed in the future to make the casting process error proof.

\section{References}

[1] Shehab $\mathrm{E}$ and Abdalla $\mathrm{H}$. Manufacturing cost modelling for concurrent product development. Robotics and Computer-Integrated Manufacturing, 2001, 17(4): 341-353.

[2] Shehab E and Abdalla H. An intelligent knowledge-based system for product cost modelling. The International Journal of Advanced Manufacturing Technology, 2002, 19(1): 49-65.

[3] Niazi A., et al. Product cost estimation: Technique classification and methodology review. Journal of Manufacturing Science and Engineering, 2006, 128(2): 563-575.

[4] Roy R., et al. Quantitative and qualitative cost estimating for engineering design. Journal of Engineering Design, 2001, 12(2): 147-162.

[5] Chayoukhi S, Bouaziz Z and Zghal A. COSTWELD: a cost estimation system of welding based on the feature model. Advances in Production Engineering \& Management, 2009, 4(4): 263-274.

[6] Chayoukhi S, Bouaziz Z and Zghal A. Cost estimation of joints preparation for GMAW welding process using feature model. Journal of Materials Processing Technology, 2008, 199(1): 402-411.

[7] Bouaziz Z, Younes J B and Zghal A. Cost estimation system of dies manufacturing based on the complex machining features. The International Journal of Advanced Manufacturing Technology, 2006, 28(3-4): 262-271.

[8] Mukherjee $\mathrm{N}$ and Ravi B. An integrated framework for die and mold cost estimation using design features and tooling parameters. The International Journal of Advanced Manufacturing Technology, 2005, 26(9-10): 1138-1149.

[9] Wasim A, Shehab E, Abdalla $\mathrm{H}$, et al. An innovative cost modelling system to support lean product and process development. The International Journal of Advanced Manufacturing Technology, 2013, 65(1-4): 165-181.

[10] Masmoudi F, Bouaziz Z, and Hachicha W, Computer-aided cost estimation of weld operations. The International Journal of Advanced Manufacturing Technology, 2007, 33(3): 298-307.

[11] Zhang Y, Zhang D, Li W et al. A manufacturing cost estimation method based on activity-based costing. International Conference on Mechanic Automation \& Control Engineering(MACE), 2010, 31(20): 3476-3479.

[12] Chougule $R$ and Ravi B. Casting cost estimation in an integrated product and process design environment. International Journal of Computer Integrated Manufacturing, 2006,19(7): 676-688.

[13] Perry N, Mauchand M, and Bernard A. Costs models in design and manufacturing of sand casting products. Advances in Integrated Design and Manufacturing in Mechanical Engineering, 2005: 69-80.

[14] Kesavan, R., Process, Planning And Cost Estimation. 2004: New Age International.

[15] Davis J R. Corrosion of aluminum and aluminum alloys. ASM International,1999.

[16] Zhang M X, Kelly P, and Gates J. The effect of heat treatment on the toughness, hardness and microstructure of low carbon white cast irons. Journal of Materials Science, 2001, 36(16):3865-3875.

[17] Pariente I, Belzunce F and Riba C Y J. Mechanical strength and fracture toughness of high chromium white cast irons. Materials Science and Technology, 2008, 24(8): 981-985.

This research work was supported by KSB Pumps, Hassanabdal, Pakistan. The research was funded by Directorate of Advanced

Studies Research and Technological Development (ASR\&TD), University of Engineering and Technology Taxila, Pakistan. 